\title{
Paradiso: Una Silogística del Sobresalto
}

I

El exceso de luz enceguece. Ante una obra como Paradiso - una autobiografía que es, también, una alegoría; unas memorias de la Cuba republicana que contienen en su centro un tratado de retórica, además de una poética de la narración, una.teoría del origen andrógino del hombre, y miles de cosas más; una novela de cajoncitos en que cada compartimento ofrece la sorpresa de una totalidad miniaturizada del cosmos; un libro varias veces cifrado, varias veces codificado, varias veces hermético-, ante un texto como el de Paradiso se despierta la tentación irresistible de declararlo oscuro, incomprensible, absurdo. La paradoja es que pocos libros como Paradiso tienen tal poder de irradiación luminosa; pocos textos contienen su propia glosa hasta un punto tal de saturación total; pocas ficciones desarrollan como ésta la espiral de sus configuraciones con tan segura intuición del camino recorrido y a recorrer. ${ }^{1}$

Pero en Paradiso, el exceso de luz actúa de máscara. Atravesada la lectura por las lanzas de símiles y metáforas, por largos párrafos de sintaxis serpentinas, por bruscas iluminaciones y visiones en que un dios habita a la vez a los personajes y a su texto, el lector se enceguece a pleno día, se hunde en el oscuro laberinto de las aclaraciones, se pierde en la glosa de la glosa de la glosa. Como todo texto auténticamente enciclopédico, como toda summa, Paradiso fracasa por la misma sobreabundancia de su éxito total. Es la suma de las victorias de cada párrafo lo que determina esa fastuosa derrota.

Texto ilegible, sí. Y por eso, texto a estar siempre leyendo, a empezar cada vez a leer, a enfrentar como si nunca antes se hubiera visto en la operación reiterada de su lectura incesante. La derrota de Paradiso es la derrota de todo texto literario verdadero: la derrota que impuso el Quijote a quienes antes lo leyeron sólo como una obra de risa, y a quienes ahora lo siguen leyendo beatamente como la Biblia de España; la derrota que impuso (que impone) Hamlet a todos sus lectores: Edipos hechizados por una Esfinge hecha de verso blanco; la derrota de las Ficciones de Borges cuyos laberintos de minuciosa sintaxis y congelada retóriça apenas si esconden el fuego devorador de su locura. Como toda la

1 Para una lectura distinta pero no antagónica de Paradiso, véase mi Narradores de esta América, II (Buenos Aires, Editorial Alfa Argentina, 1974), pp. 130-155. Se recogen allí dos textos de 1966 y 1967 sobre esta novela. 
literatura que vale, el texto de Paradiso fracasa en su nivel primario de total inteligibilidad para triunfar (y de qué manera) en el nivel de una inteligibilidad siempre perseguida en sucesivas lecturas, en sucesivas re-escrituras.

Por eso, el intento que ahora hago sobre el texto de Paradiso - un intento deliberadamente limitado- acepta desde el principio esa derrota de la obra que es, naturalmente, la derrota de su lectura. Consciente por completo de que la clave de Paradiso no existe, aunque existen sí las claves; asumiendo todo el riesgo de una lectura parcial, y por lo tanto, a tientas, y por lo tanto provisoria, y por lo tanto, en borrador, esta aproximación al libro busca (apenas) definir una de sus vías de acceso: la que se centra en una teoría de la visión poética, que es a la vez clave para la definición del nivel anecdótico de la obra (la educación del protagonista, José Cemí) y clave para insertar la retórica que subyace el texto, dentro del texto mismo en su deslumbrante, enceguecedora luminosidad.

Paradiso concluye con una palabra: empezar. ${ }^{2}$ El verbo elegido deliberadamente por. Lezama indica la naturaleza circular, de lectura infinita, que es una de las características textuales más notables de la obra. En el contexto en que ocurre esta última palabra, $\mathrm{em}$ pezar apunta evidentemente a la práctica de la poesía, a la escritura de la poesía, que José Cemi siente como tan cercana, tan inmediata, que ya empieza a ser posible. En una cafetería, solo en la madrugada, Cemí escucha a alguien jugar con la cucharilla en el vaso. Entonces reconoce un ritmo musical. En efecto, un ritmo que ya es sílaba y pronto habrá de convertirse en palabras, nace de ese golpeteo, para el oído de Cemí. En ese código Morse de la cucharilla contra el vaso deja el texto su cifra: Después de 617 páginas el lector ha llegado al punto en que la irresistible vocación poética de Cemí es una evidencia. Por eso, la obra termina en el momento en que el protagonista va a empezar su obra: otra, o la misma, eso por ahora no importa.

También el Portrait of the Artist as a Young Man, de Joyce; también $A$ la recherche $d u$ temps perdu, de Proust, terminaban en el momento en que sus sendos protagonistas descubrían el mundo inagotable de su vocación y la forma de la obra futura. Pero si traigo ahora estos ejemplos (tantas veces invocados por la crítica al hablar de Paradiso) no es para indicar una filiación reconocida sino para situar el texto en un contexto más general. Cemí descubre su vocación; Cemí, el poeta, descubre el producto poético; Cemí deja de ser Cemí para convertirse en el descubridor del ritmo. Los dos niveles en que constantemente se mueve esta novela quedan sutilmente indicados aquí: el nivel de la narración anecdótica (un joven habanero en la madrugada de una cafetería) y el nivel de la alegoría (el poeta inventa ritmo).

Pero para poder comprender por qué la obra se cierra aquí, y no un poco antes o un poco después, hay que mirar en qué contexto inmediato ocurre ese episodio final, tan significativo. Cemí ha llegado a la cafetería una noche en que algo, un impulso que no define y que podría calificarse simplemente de sobrenatural, lo ha hecho salir a recorrer las calles, a descubrir una casa enceguecedoramente iluminada, a entrar en ella y ver que allí

2 He consultado la primera edición de Paradiso (La Habana, UNEAC, 1966), y por ella cito. 
se estaba velando el cadáver de su amigo y mentor, Oppiano Licario. Como todas las apariciones de este personaje en la novela (y son apenas cinco), ésta última también lleva el signo de lo mágico. Impulsado por una mano invisible, Cemí ha venido a esta última cita con el taumaturgo: ha venido para recoger el poema que la hermana de Oppiano Licario le entrega, el poema último que ha escrito el muerto y que se. llama, naturalmente, José Cemi.

No lo llamo, porque él viene, como dos astros cruzados en sus leyes encaramados la órbita eclíptica tiene.

Yo estuve, pero él estará, cuando yo sea el puro conocimiento, la piedra traída en el viento, en el egipcio paño de lino me envolverá.

La razón y la memoria al azar verán a la paloma alcanzar la fe en la sobrenaturaleza.

La araña y la imagen por el cuerpo, no puede ser, no estoy muerto. Ví morit a tu padre; ahora, Cemí, tropieza.

Inútil analizar el poema línea a línea. Eso quedará para otra ocasión. Lo que sí me importa es una de sus significaciones más obvias: por medio del poema - el último texto que escribe Oppiano Licario antes de morir - su destino de guía, de maestro, de mentor, se cumple y realiza finalmente: el poema trasmite el testamento de Oppiano Licario, testamento dirigido a un solo ser, a aquel que de algún modo lo continuará, cumplirá su obra, la perfeccionará. Bautista del nuevo Cristo que es José Cemi - ya la crítica ha apuntado la coincidencia de las iniciales J.C. y hasta el hecho de que el primer encuentro real de Cemí y Oppiano Licario se produzca por medio de un reconocimiento de esas iniciales de fuego-, el poema es el documento formal por el que el maestro de poesía y de poética deja a su discípulo la clave del ritmo. De ahí que Cemí, al quedarse solo en la noche de la cafetería, reconoce en el ritmo de la cucharilla en el vaso la música del poema. Ahora se pueden leer completas las últimas frases del libro:

Impulsado por el tintineo, Cemí corporizó de nuevo a Oppiano Licario. Las sílabas que oía eran ahora más lentas, pero también más claras y evidentes. Era la misma voz, pero modulada en otro registro. Volvía a oír de nuevo: ritmo hesicástico, podemos empezar. (p. 617) 
III

Es claro, podemos empezar. Y empecemos por una pregunta: ¿Quién era Oppiano Licario? De todos los numerosos personajes del libro, Oppiano Licario es el único (con excepción de los del capítulo XII, de los que hablaré luego) que no aparece insertado en el texto con las precauciones habituales de nombre, identificación y circunstancia. Es el personaje misterioso, el joker de esta deslumbrante baraja lezamiana, que es jugado cuándo y dónde menos se le espera y que, sin embargo, o tal vez por eso mismo, adquiere en cadá ocasión un valor singularísimo.

La primera vez que aparece es en el capítulo IV, como parroquiano anónimo de un cafetín de homosexuales al que ha ido a parar, sin saberlo, Alberto Olalla, 'el joven tío de Cemí, un alegre perdulario que ya está tocado por la locura poética. La segunda vez, es en el capítulo IV y se identifica como paciente en el mismo hospital norteamericano en que está muriendo el padre de Cemí. Oppiano Licario tiene con éste una conversación sorprendente, y absolutamente necesaria, como son las mejores conversaciones del libro. Por ella, se entera el lector que el paciente era el mismo parroquiano anónimo del Cafetín. Ambas veces Oppiano Licario actúa por su presencia en una escena en que otro es el protagonista pero su presencia tiene un valor catalítico: permite al padre morir envuelto en el sonido de una voz cubana que responde a su voz cubana en el ambiente doblemente extranjero de un hospital norteamericano; también permite al tío escapar de la burla grosera de los homosexuales y lo orienta hacia la sexualidad normal.

En ambos episodios, la presencia de Oppiano Licario da a cada episodio el significado de un rito iniciático. Es el sacerdote de dos ritos fundamentales de la vida humana. Asiste al padre a morir; asiste al tío en la hora de la iniciación sexual. Como sacerdote de una religión subterránea, o tal vez sólo olvidada, Oppiano Licario está allí, en el momento crucial. Pontífice, en el sentido etimológico del término, Oppiano Licario construye invisible el puente que habrá de llevar al padre a la muerte, al tío al goce sexual.

La tercera aparición de Oppiano Licario en la vida de Cemí prescinde de intermediarios. En el capítulo trece ocurre el encuentro directo con José Cemí, en un ómnibus; encuentro que Lezama detalla en clave burlesca: un hombrecito roba a Oppiano Licario unas monedas antiguas, Cemí las restituye sin que Oppiano parezca advertirlo; cuando Cemí llega a su casa encuentra en su bolsillo una tarjeta en que Oppiano le agradece la restitución, se identifica como conocido de sus parientes y le da una cita. La clave burlesca no debe hacer olvidar la mágica. Porque no se trata (sólo) de un juego paródico, de una irrisión; el ómnibus también es la nave de los locos, el barco en que todos navegamos, y el tráfico ilegal de la moneda es el símbolo del tráfico ilegal de la vida. Pero es sobre todo, el símbolo de la predestinación que a través de los caminos laberínticos de encuentros y desencuentros con otros parientes, impulsa a dos seres a aproximarse ciegamente, como peces en lo profundo del mar, como duelistas en la niebla, como murciélagos movidos por oscuro radar. La moneda - ese signo que cambia de mano en mano y que llega hasta Oppiano Licario desde la antigüedad griega - es el instrumento que lo lleva a encontrarse con Cemí.

El encuentro es mágico porque estaba predestinado. Ya al encontrar al tío y luego al padre, Oppiano Licario estaba entrando en la órbita de Cemí, 
como dos astros cruzados

en sus leyes encaramados

dirá su poema. Y nada más cierto: el papel de sacerdote iniciador de un culto subterráneo lo cumple Oppiano Licario a partir de esa presencia insólita en ocasión de la muerte del padre o de la iniciación sexual del tío. Ahora, Oppiano Licario presidirá otra iniciación: la de José Cemí en el orbe de la poesía. La cita que la tarjeta propone se cumple en las dos últimas páginas del capítulo penúltimo, el trece:

Licario le abrió de inmediato la puerta sin necesitar de llamada. La pieza era muy distinta de lo que él había visto desde el séptimo piso. No había nadie en el interior. Sólo. la mesa, con el triángulo de bronce y una varilla metálica para provocar la sonoridad. Vibraron los dos metales. Oppiano Licario presentaba un pantalón negro y una camisa muy blanca. Licario, mientras se prolongaba la vibración exclamó: -Estilo Hesicástico.

-Veo, señor, le dijo Cemí, que usted mantiene la tradición del ethos musical de los pitagóricos, los acompañamientos musicales del culto de Dionisos. -Veo, le dijo Licario con cierta malicia que no pudo evitar, que ha pasado del estilo sitáltico, ode las pasiones tumultuosas, al estilo hesicástico, o del equilibrio anímico, en muy breve tiempo.

Licario golpeó de nuevo el triángulo con la varilla y dijo: Entonces, podemos ya empezar. (pp. 562-563)

La alusión al cambio de estilo es una referencia, en broma, al encuentro anterior en que Cemí había rescatado las monedas en medio de las pasiones tumultuosas del ómnibus. Pero ahora, Cemí y Oppiano Licario se encuentran en el espacio mágico de la habitación del segundo. La iniciación poética puede ya comenzar.

Parece irresistible vincular este proceso del encuentro de Cemí con Oppiano Licario con las etapas del acercamiento a la presencia divina en la Divina Comedia, o (si se prefiere un modelo más breve y modesto de iniciación) con el relato de Borges, "El acercamiento a Almotásim". También en este cuento, el estudiante llega a la presencia inimaginable de Almotásim a través del encuentro con seres que han conocido a Almotásim y en los que se advierte como un resplandor dejado por aquella ausencia. Aquí el que parece acercarse (invisible en su luz) es Oppiano Licario pero el sentido iniciático no está invertido del todo ya que en el tramo final, Cemí acude a Oppiano, que abre la puerta y lo hace entrar.

También como en Borges, como en Dante, la ęscena se congela en el momento en que se va a iniciar el rito. Porque el rito es secreto y sólo puede ser realizado en secreto. Las últimas palabras del encuentro ("podemos ya empezar"), ' y la música pitagórica de estilo hesicástico que le sirve de fondo, anticipan las últimas palabras de la novela: acordándose de su maestro, Cemí escuchará el golpeteo de la cucharilla en el vaso y se dirá (citará): "podemos empezar'”. 


\section{IV}

Si al lector le está prohibido el acceso a la ceremonia iniciática misma, si el rito sólo aparece como una ausencia, el vaciado de la forma, y no la forma misma, hay suficientes claves en el texto de Paradiso para poder reconstruír la poética que subyace ese rito de Oppiano Licario. El mismo la define en varios pasajes del capitulo final, el catorce. Conviene repasar sus momentos culminantes. Evocando una conversación familiar, se dice alli:

Licario había acabado de hablar con su hermana, con un silogismo de sobresalto, con lo que era una de sus más reiteradas delicias, demostrar, hacer visible algo que fuera inaceptable para el espectador, o provocar dialéticamente una iluminación que encegueciese por exceso de confianza al que oía, en sus conceptos y sensaciones más habituales y adormecidas. (p. 567)

Queda aquí esbozado un método que más adelante, Oppiano Licario desarrolla con pausa: el método de una dialéctica similar a la socrática en su finalidad y hasta en su raíz pero opuesta por la vía elegida. En vez del pensamiento racional (el silogismo lógico), Oppiano Licario practica un pensamiento mágico (el silogismo de sobresalto). En ưna de sus líneas - adviértase que digo: una - ese silogismo se vincula con el pensamiento, tan citado por Lezama, de Tertuliano: Credo quia absurdum: Porque es absurdo, creo. $\mathrm{O}$ como dice Oppiano:

...hacer visible algo que fuera inaceptable al espectador, o provocar dialécticamente una iluminación que encegueciese...

Un poco más adelante, Oppiano Licario elabora con ejemplos su teoría del silogismo poético:

Partía de la cartesiana progresión matemática. La analogía de dos términos de la progresión desarrollaba una tercera progresión o marcha hasta abarcar el tercer punto del desconocimiento. En los dos primeros términos pervivía aún mucha nostalgia de la sustancia extensible. Era el hallazgo del tercer punto desconocido, al tiempo de recobrar, el que visualizaba y extraía lentamente de la extensión la analogía de los dos primeros móviles. El ente cognoscente lograba su esfera siempre en relación con el tercer móvil errante, desconocido, dado hasta ese momento por las disfrazadas mutaciones de la evocación ancestral. (pp. 576-577)

Queda al descubierto aquí esa dialéctica de la iluminación que procede por analogía pero se dispara, con intolerable tensión, hacia el tercer punto desconocido o errante. Un poco más abajo, la definición se aclara:

Así, en la intersección de ese ordenamiento espacial de los dos puntos de analogía, con el temporal móvil desconocido, situaba Licario lo que él llamaba la Silogística poética. Se apoyaba en un silogismo del Dante, que aparece en su De Monarchia, 
donde la premisa menor, "Todos los gramáticos corren", lograba recobrar en un logos poético sobre la lluvia de móviles no situables, puntos errantes y humaredas, no dispuestos sino a enmallarse en dos puntos emparejados de una irrealidad gravitada como conclusión. Otras veces, ese tercer punto errante, enclavado en su propia identidad, lograba crear una evidencia reaparecida, distanciada las más de las veces de la primera naturaleza en su realidad. (...) En otras ocasiones, el tercer móvil del desconocimiento, revela a través de la ofuscadora seguridad de una forma, aparentemente dominada por las mallas de la analogia, su conversión en un cuerpo no subordinado a los tres puntos anteriores, pues aquella inicial morfologia iba a la zaga de una esencia esperada, cuando de pronto el resultado fue la presencia de otro neuma que aseguró su forma misteriosamente. (p. 577)

La silogistica poética asegura, a través de una dialéctica que no es lógica sino mágica, el encuentro con el tercer móvil desconocido, el tercer punto errante, la conversión en otro (cuarto) punto misterioso. Es decir: asegura el acceso a otra dimensión de la realidad, la captación de una (otra) naturaleza;, esa sobrenaturaleza a la que alude tantas veces el texto lezámico. El esfuerzo se vincula, naturalmente, no sólo con la experiencia religiosa (y de ahí la necesaria mención de Dante) sino con la experiencia poética más radical, la de un poeta como Lautréamont. ¿Qué otra cosa que un silogismo poético es ese encuentro del paraguas y la máquina de coser sobre la mesa de disección que tanto ha servido de bandera de la poesía de la modernidad? Para un lector de Paradiso es innecessario evocar esas deslumbrantes comparaciones del texto lezamesco que saltan de una analogía a otra para clavarse, como un lanzazo de luz, en ese tercer punto desconocido que es el blanco invisible del silogismo poético. El propio Licario habrá de apuntar a esa retórica del símil en unas líneas que se encuentran más abajo del texto ya citado:

Licario estaba siempre como en sobreaviso de las frases que buscan hechos, sueños o sombras, que nacen como incompletas, y a las que vemos el pedúnculo flotando en la región que vendría con una furiosa causalidad a sumársele. Ellas mismas parecen reclamar con imperio grotesco o majestuoso una giba o un caracol que las hacía sonreír, siguiendo después tan orondas como si fuese su sabat costumbroso.

Estas sentencias no quedan nunca como verso ni participación en metáfora, pues su aparición era de irrupción o fraccionamiento casi brutal, y necesaria en esa llegada parecía borrar la compañía, hasta que después comenzaba a lucir sus temerarias exigencias de completarse. Era el reverso del verso o la metáfora que vienen de nacimiento con su sucesión y sus sílabas rodadas. (pp. 578-579)

Y a continuación, Licario cita varias frases de ese tipo. Veamos la última:

Una vez oyó: diez mil mastines tienen que ser ejecutados, y comenzó por atravesar unas tierras feudales, habitando unas estaciones de garduñas del sacro imperio y de corzas oyendo misas. (p. 579) ${ }^{3}$

3 Tal vez se encuentre en este pasaje el comienzo de 62. Modelo para armar, la entretenida novela de Julio Cortázar (Buenos Aires, Sudamericana, 1968). 
La teoria de Licario y la práctica de Licario son una con la teoría y práctica de Paradiso; es decir: de Lezama. Por eso es posible encontrar en declaraciones de éste a Armando Alvarez Bravo una explicitación diferente pero complementaria del silogismo poetico. ${ }^{4}$ Me excuso por citar estas palabras, tan citadas por la crítica, porque creo que ellas adquieren otro sentido cuando se las vincula con el texto, los textos, de Oppiano Licario; al hablar de la imagen y la metáfora, Lezama aclara el contexto teórico en que hay que inscribir la teoria de Licario:

Es uno de los misterios de la poesía la relación que hay entre el análogo, o fuerza conectiva de la metáfora, que avanza creando lo que pudiéramos llamar el territorio substantivo de la poesía, con el final de este avance, a través de infinitas analogias, hasta donde se encuentra la imagen, que tiene una poderosa fuerza regresiva, capaz de cubrir esa sustantividad. (...) Yo creo que la maravilla del poema es que llega a crear un cuerpo, una sustancia resistente enclavada entre una metáfora, que avanza creando infinitas conexiones, y una imagen fínal que asegura la pervivencia de esa sustancia que es la poiesis. (pp. 56-57)

Lo que aqui dice Lezama de la metáfora, que avanza por analogías hacia la imagen, y la imagen que asegura la pervivencia de la poesía, puede vincularse a ese silogismo poético que había ilustrado Licario. El método expresado, o definido, por el personaje se enlaza con la teoria del autor. La tecnése vuelve poiesis. Pero el movimiento interior es el mismo y la conclusión final, ya sea en el plano de la investigación apasionada, la busca ardiente, la flecha disparada hacia el blanco, ya sea en la contemplación crítica de esa misma operación, el disparo estudiado desde el blanco mismo, la conclusión final muestra (una vez más) la coincidencia absoluta de las articulaciones del texto entero de Lezama, dentro y fuera de Paradiso. Porque cuando aquí se habla de Lezama se habla (es claro) de un texto.

Que José Cemí estaba más que preparado para recibir la enseñanza de Oppiano Licario es algo que la novela deja perfectamente en claro. Lo documentan no sólo sus experiencias existenciales, desde la muerte y resurrección incesante que se produce con los frecuentes ataques de asma de la niñez, hasta su apasionada fusión y confusión con los dos amigos, Fronesis y Foción con los que compone una triada, o trinidad dialéctica (tres caras de una misma investigación del ser, tres faces de un mismo ser), sino que lo documenta aún más toda esa sucesión de instantes de revelación, iluminación, visitación de lo sobrenatural que acompanan su desarrollo. Son tantos y tan intensos esos momentos de epifanía que bastará indicar, a via de ejemplo, algunos:

----la brutal experiencia a que lo somete su padre, cuando lo echa al agua para que aprenda a nadar, sostenido sólo por el dedo índice del padre, que al fin lo abandona $y$, por unos horribles momentos, lo deja hundirse en el agua; experiencia que se

4 Esta entrevista de Lezama Lima con Alvarez Bravo fue publicada originariamente en Orbita de Lezama Lima (La Habana, UNEAC, c. 1966). Está recogida en Recopilación de Textos sobre José Lezama Lima, selección y notas de Pedro Simón (La Habana, Casa de las Américas, 1970). Tomo de esta última la cita. 
multiplica en otra del padre con la hermana y en una brutal cura contra el asma (capitulo VI);

----los cuentos de la abuela sobre muertes familiares y muertes de santos que asumen en el relato de ella un carácter sobrenatural e imponen sus visiones pesadillescas al niño (capitulo VI);

-----el juego de yaquis en que se dejan absorber los niños y que la madre también comparte hasta el punto de ver, en un determinado momento, dibujada en el espacio mágico creado por las piedritas, la cara del difunto padre (capítulo VII); --.--la carta del tío Alberto que abre para el niño las compuertas del lenguaje metafórico y anticipa con su práctica delirante de la imagen no sólo el simbolismo fálico del famoso capítulo VIII sino la silogística poética misma de Oppiano Licario (capítulo VII);

-----una partida de ajedrez que el mismo tío Alberto convierte en una justa poética medieval y que es también clave del mismo sistema poético (capítulo VII);

-----el diálogo con la madre en que ésta le da un único consejo básico: seguir el camino difícil, seguir una obsesión propia que busque lo oculto, lo secreto; ese diálogo prepara a Cemí para el encuentro con Licario; de la mano de la madre pasará. en el.plano simbólico, a la mano del mentor, de la matriz al sacerdote del culto iniciático de la poesía (capítulo IX);

-----esa primera visión que tiene Cemí de los caballos de la Fortaleza que parecen surgir del fondo de la historia, o de algún cuadro renacentista (capítulo IX); ----al final de ese mismo capítulo, esa larga discusión sobre homosexualidad que concluye con otra visión de Cemí: por las calles de La Habana desfila una procesión romana. Es el culto del dios Príapo, el inmenso falo coronado. El texto de la novela habanera se contamina de esa sobrerrealidad histórica que en el capitulo XII romperá los límites narrativos para albergar historias de distintos tiempos y distintos personajes, completamente desconectados de la historia central.

O mejor dicho: sólo conectados por la fuerza del silogismo poético (capítulo IX).

¿A qué seguir? Habría que recorrer la novela página a página porque ya no se trata de visiones o revelaciones: la textura misma de cada frase, la urdimbre de las mismas, la mecánica de su inserción en el texto de Paradiso y en el texto total, aún más laberintico de Lezama, requieren un análisis pormenorizado que es imposible realizar aquí.

Lo que sí puede y debe indicarse ahora es la perfecta adecuación de cada uno de los hilos de esa trama que se va tejiendo hacia atrás desde y a partir de Oppiano Licario, en el último capítulo de la novela, y que en virtud de esa circularidad a la que alude Lezama cuando habla de la "evidencia reaparecida", permite desandar el camino llevando como guía a Licario. Entonces se advierte que el sistema de éste es clave del sistema del libro y que el mentor aparece al fin cuando las experiencias existenciales y sobrenaturales de Cemí lo han preparado para el encuentro final con la luz deslumbradora del silogismo poético. Licario abre la puerta para que Cemí entre. Entonces, podemos ya comenzar, dice. Entonces, Cemí puede comenzar. Entonces, el libro puede comenzar. Es decir: concluír, que es lo mismó. 
La circularidad apunta, en otra dimensión, a una teoria que está sólo aludida en los textos que hemos invocado pero que otros textos de Lezama permiten iluminar: es la teoría cristiana de la resurrección. El poema que Licario dedica, a las puertas de la muerte, a Cemí contiene la clave no sólo de su mortalidad sino de su eventual resurrección. Allí dice:

pero también agrega:

yo estuve, pero él estará

El poema reafirma:

la fe en la sobrenaturaleza.

El poema asegura:

no puede ser, no estoy muerto.

En declaraciones suficientemente difundidas, Lezama ha opuesto la concepción heideggariana del "ser para la muerte" a la concepción cristiana del ser para la resurrección. Y en otras declaraciones sobre la novela que está escribiendo y con la que continuará Paradiso ha sido muy explícito: Oppiano Licario volverá a vivir en la realidad del texto. Se ha ido pero no ha desaparecido. ${ }^{5}$ Estas declaraciones externas al texto mismo de Paradiso encuentran sin embargo su confirmación dentro de la obra. Porque el libro se propone básicamente ilustrar aquella dimensión de la realidad que es sobrenatural y mágica. En esa dimensión, no rigen las leyes científicas de una visión naturalista sino otras leyes, las del silogismo poético, que permiten no sólo el salto hacia el tercer término desconocido, sobrerreal, sino el regreso hacia atrás, a una dimensión desconocida de los términos de la analogia primaria. En una circularidad que cierra el libro en el momento en que se abre ("podemos ya empezar") el ejercicio de la poesía; que postula una actividad cuando esa misma actividad está a punto de cesar, la inmortalidad del texto, y de todas las figuras del texto (sean "personajes" o metáforas, silogismos o símiles, "cuadros" o "visiones"), la inmortalidad poética está asegurada.

Hay una resurrección no sólo al nivel de la historia (continúe o no Lezama esta historia hasta el final en otro libro) sino la resurreción al nivel del texto primario y básico de Paradiso. La palabra "empezar" no es paradojal: el texto realmente empieza alli y por eso su lectura puede iniciarse hacia atrás en la página misma que marca con su espacio en blanco el final.

\section{VII}

Una última observación: esa lectura hacia atrás que la última palabra del texto sugiere, esa inversión del orden normal de lectura, se liga profundamente con la naturaleza retórica misma del libro y con la visión à rebours de Lezama. Porque si existe alguna dificultad para clasificar este libro como novela es porque esa forma ha sido generalmente considerada desde una perspectiva impuesta por el realismo. Pero si se abre la perspectiva y

5 Véase la entrevista citada con Alvarez Bravo, pp. 2\%-29. 
se busca otra concepción de la novela--una concepción que permita incorporar no sólo las obras experimentales de este siglo, a partir del Ulysses o los textos de Kafka, sino toda esa literatura marginal de Occidente y que ilustran el Satiricón, Gargantua, el Quijote, Tristram Shandy, Les Chantes de Maldoror-es la concepción de una narrativa carnavalesca, de una apotesosis de la irrisión y de la parodia que burla y celebra a la vez el mundo real, lo que permitiría situar a Paradiso en sus exactas coordenadas.

Los estudios de Mikhail Bakhtine sobre Rabelais y Dostoievski, su concepción de la literatura carnavalesca y de la novela dialogística, permitizían entonces reconocer un camino de acceso que uniera definitivamente la visión dispersa del lector ingenuo de Paradiso con la visión centrada del crítico. ${ }^{6}$ Entonces, la burla y la parodia lezamesca no se verian como lo extravagante que irrumpe en una novela familiar y autobiográfica para destruírla, sino como el signo más explícito posible de esa realidad poética que es (como la del Carnaval) a la vez celebración y blasfemia, exaltación y befa, consagración y destrucción. El espíritu medieval que atraviesa el pensamiento y la imaginería del texto lezamesco adquiriría entonces sentido. Su barroco que es también gótico, se situaría en una nueva perspectiva. Hasta esa prodigiosa metaforización de la potencia fálica (que tanto ha molestado a las beatas de ambos sexos) resultaría la visión normal carnavalesca.

Pero no sólo esto: el silogismo poético del sobresalto en que se resume la teoría poética del texto de Oppiano Licario y, por lo tanto, del texto lezamesco, adquiriría entonces un doble sentido unificado: en esa búsqueda del sobresalto es esencial la inversión. Lo que está arriba va a ir abajo; lo que está abajo, arriba. De la misma manera que el loco es coronado rey en Carnaval, y los excesos más groseros de la carne (la fornicación bestial, la sodomía, pero también la defecación) encuentran sentido en el Carnaval, esos mismos excesos, metamorfoseados por la escritura lezamesca, encuentran su sitio en la visión invertida y, a la vez, correcta. Se alcanza así una visión del Paradiso que no excluye sino que incluye a su Inferno: se realiza la visión puramente dialéctica de la metáfora que por sucesivas series analógicas desemboca en una imagen final y doble. Esa es la visión total que opera el silogismo poético. de Oppiano Licario, de José Cemí, de José Lezama Lima.

6 Una útil discusión de Bakhtine se encuentra en el trabajo de Julia Kristeva, "Le mot, le dialogue et le roman", originariamente publicado en Critique (1966) y recopilado luego en Semiotique, Recherches pour une sémanalyse (Paris, Editions du Seuil, 1969), pp. 143-173. Vale la pena consultar también el trabajo de Severo Sarduy, "El barroco y el neobarroco", recogido en el libro colectivo, América Latina en su Literatura, coordinación e introducción de César Fernández Moreno (México, UNESCO/Siglo XXI, 1972); véase especialmente las pp. 174176. 
